$15^{\text {th }}$ International Conference on

AEROSPACE SCIENCES \& AVIATION TECHNOLOGY,

$\boldsymbol{A S A T}$ - 15 - May 28 - 30, 2013, Email: asat@mtc.edu.eg,

Military Technical College, Kobry Elkobbah, Cairo, Egypt,

Tel: +(202) 24025292 -24036138, Fax: +(202) 22621908

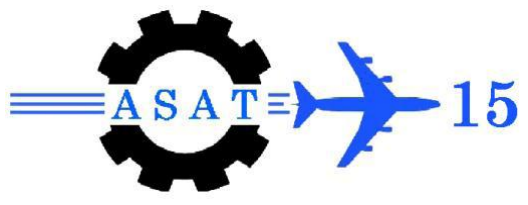

\title{
Structural Design of Agricultural Aircraft Fuselage
}

\section{A. M. Jubartalla ${ }^{*}$ and I. A. Yousif ${ }^{\dagger}$}

Abstract: This paper aims to calculate the fuselage loads, and analyzing the structure to determine the margin of safety.

Configuration of the aircraft was completed and frozen as addressed in a previous publications [1]. However, the aircraft should meet the agricultural requirements in Sudan. It could be manufactured locally and equipped with an engine that works with cheaper type of fuel (Jet-A1). Preliminary arrangement and sizing of structural component of fuselage has been done.

FEM software of ABAQUS® used for structure modeling and analysis, hence the shear forces and bending moment diagrams have been obtained. Accordingly, the working shear and bending stresses within the flight envelope have been calculated.

The margin of safety is found to be positive along the fuselage structural parts, which shows good enough strength.

Keywords: Agricultural aircraft, preliminary design, sizing, fuselage, structure, loading, margin of safety, numerical analysis and strength calculation.

\section{Nomenclature}

C Chord

FEA Finite Element Analysis

FEM Finite Element Methods

n Load Factor

S Wing Area

v Velocity

W Weight

\section{Introduction}

Aerial structures should possess two features, high strength and low weight. That means, an accurate loading is required, i.e. wind tunnel test data. But in this case the standard loads have been applied namely JAR-VLA as wind tunnel data was not available [2]. For purposes of simplifying the problem, the applied load is aerodynamic loads from horizontal and vertical tail stabilizers and also weight of engine, nose wheel, payload and the pilot.

\footnotetext{
* Co-Researcher, Aeronautical Research Center, Khartoum- Sudan; jubara66@ hotmail.com

${ }^{\dagger}$ Researcher, Aeronautical Research Center, Khartoum- Sudan; smileyousif@gmail.com
} 
The JAR-VLA described the method which can be used to calculate the loads on fuselage. In this method, using parameter $\left(\mathrm{n} \frac{\mathrm{W}}{\mathrm{S}}\right)$, the load distribution along the chord of each section of vertical or horizontal tails can be drawn. The area under the curve of each section was equal to the amount of distributed load in that section, so the amount of distributed load on the root of each horizontal or vertical tails could be obtained.

Main specifications, 3-views drawing and the V-n diagrams of SEAD-8 aircraft are represented in Table (1), Fig. (1) and Fig. (2), respectively.

Table 1. SEAD-8 Aircraft specifications [1]

\begin{tabular}{c|c}
\hline \hline Name of project & SEAD-8 \\
\hline Payload (liquid chemical) & $1000[\mathrm{Kg}]$ \\
Crew weight (one pilot) & $100[\mathrm{Kg}]$ \\
Range & $740[\mathrm{Km}]$ \\
Endurance & $3[\mathrm{Hours}]$ \\
Initial rate of climb & $6[\mathrm{~m} / \mathrm{Sec}]$ \\
Service ceiling & $3[\mathrm{Km}]$ \\
Absolute ceiling & $7.62[\mathrm{Km}]$ \\
Field length & $1-1.2[\mathrm{Km}]$ \\
Field width & $10-15[\mathrm{~m}]$ \\
\hline
\end{tabular}

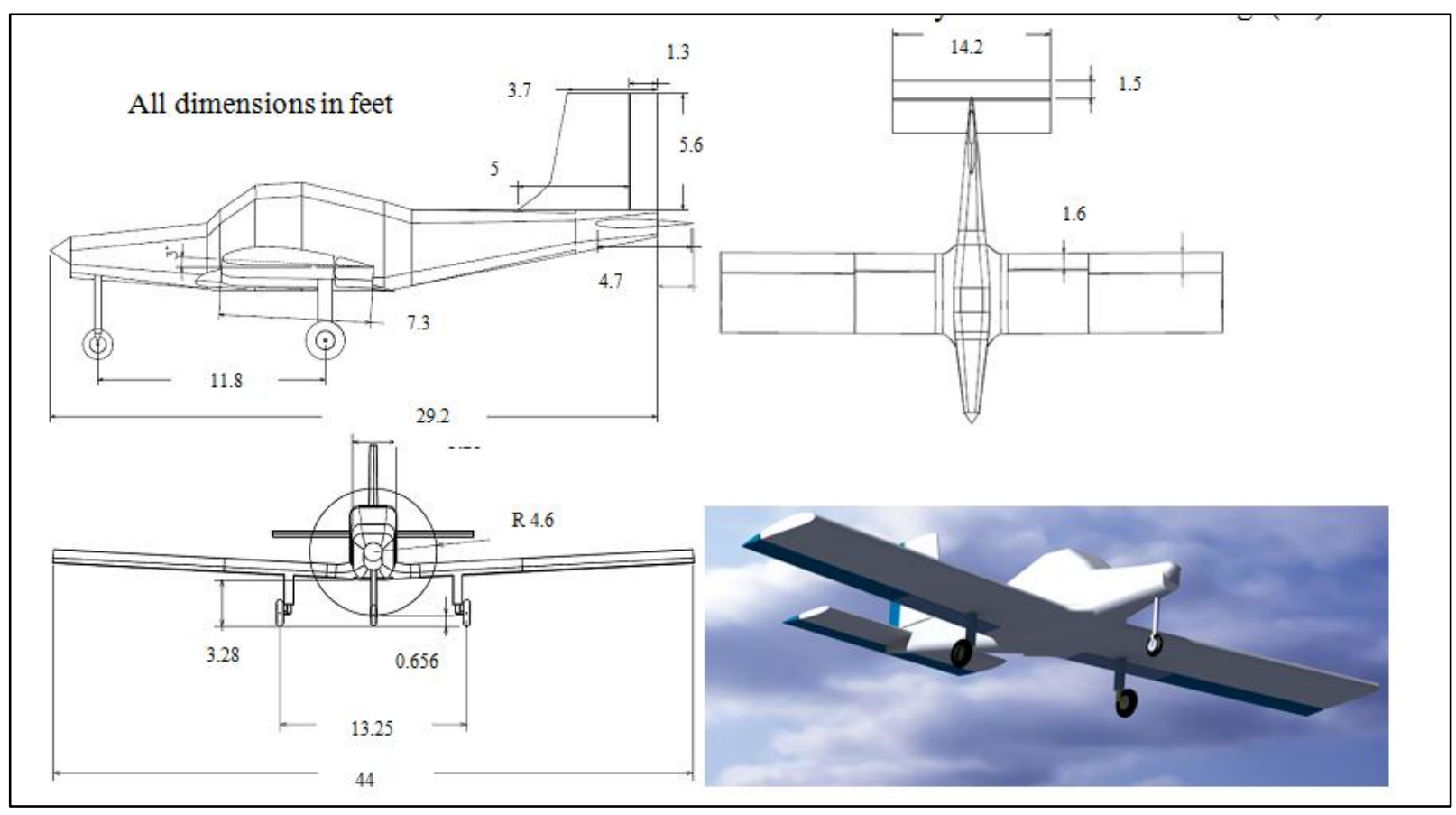

Fig. 1 SEAD aircraft 3-views [1] 


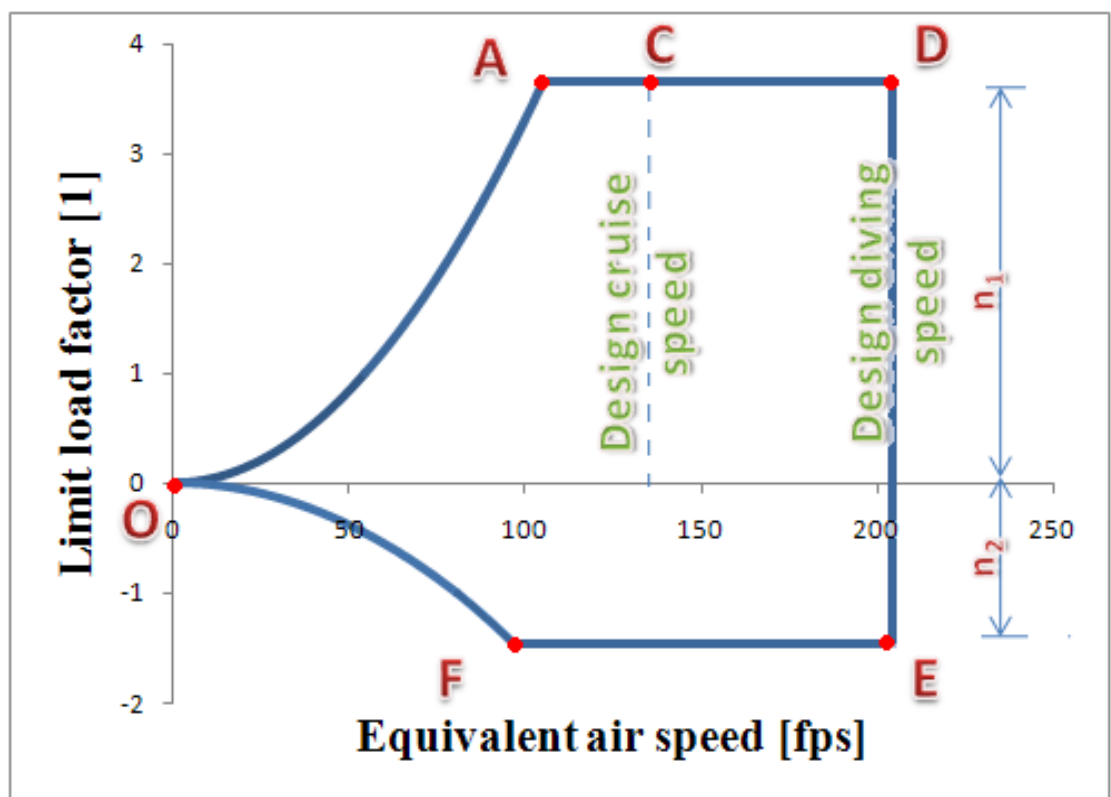

Fig. 2 Sead-8 V-n diagram [3]

Load distribution along the chord in the section of horizontal and vertical tail's root was drawn based on the above mentioned method.

\section{Force Calculations}

For tail unit, after determining aerodynamic load distribution, shearing force, bending and twist moments of each section of tails can be obtained from equations (5), (6) and (7), respectively.

The configurations of horizontal and vertical stabilizers have rectangular shape and it was difficult to calculate the forces and moments. To solve this problem an alternative and analog shape with equal area and symmetrical main axis has been used, stiffness and aerodynamic centers can be expressed in equations (8) and (9), respectively. At the last, bending and twist moments in each section of horizontal and vertical tails can be determined by integrating the distributed moments for horizontal and vertical tails. Figure (3) shows the distribution of force along the chord of horizontal and vertical tails.

Finally the fuselage will support the tail surfaces at the attachments which coincide approximately at root chord of these surfaces. Thus shear force, bending and twisting moments will be taken from root at $(\mathrm{y})=0$.

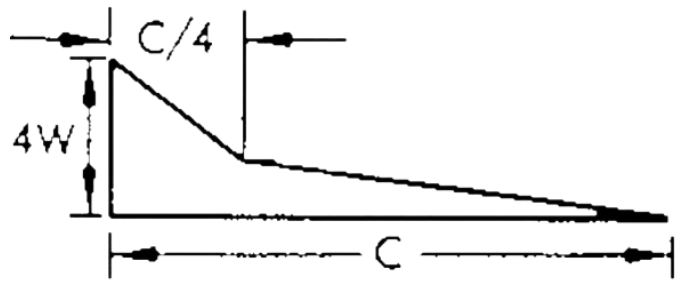

Fig. 3 Chord-wise distribution of tail surfaces [2] 
The aerodynamic loads, namely pressure distribution, can be neglected in comparison to tail, payload and engine loads. Table 2 below shows the applied loads to the aircraft.

Table 2 Loads applied on fuselage

\begin{tabular}{c|c}
\hline \hline Mass of Equipment & Mass [kg] \\
\hline Payload & 1000 \\
Engine + Nose wheel & 300 \\
Crew & 90 \\
\hline \hline
\end{tabular}

\section{Equations}

$$
\begin{aligned}
& \overline{\mathrm{w}}=4.8+0.109\left(\mathrm{n} \frac{\mathrm{w}}{\mathrm{s}}\right) \\
& \frac{\mathrm{y}^{2}}{\mathrm{~b}^{2}}+\frac{\mathrm{H}_{\mathrm{y}}^{\mathrm{p}}(\mathrm{y})^{2}}{\mathrm{a}^{2}}=1 \\
& \frac{\mathrm{y}^{2}}{2.165^{2}}+\frac{\mathrm{H}_{\mathrm{zhor}}^{\mathrm{p}}(\mathrm{y})^{2}}{64.84^{2}}=1 \\
& \frac{\mathrm{y}^{2}}{1.70688^{2}}+\frac{\mathrm{H}_{\mathrm{y}}^{\mathrm{p}}(\mathrm{y})^{2}}{54.02^{2}}=1 \\
& \mathrm{Q}_{\mathrm{z}}^{\mathrm{p}}(\mathrm{y})=\int_{0.5 \mathrm{~b}_{\mathrm{H}}}^{\mathrm{Z}} \mathrm{H}_{\mathrm{z}}^{\mathrm{p}}(\mathrm{y}) \mathrm{dy} \\
& \mathrm{m}_{\mathrm{b}}^{\mathrm{p}}(\mathrm{y})=-\mathrm{H}_{\mathrm{Z}}^{\mathrm{P}}(\mathrm{y}) *\left(\mathrm{X}_{\mathrm{o} . \mathrm{j}}(\mathrm{y})-\mathrm{X}_{\mathrm{c} . \mathrm{p}}(\mathrm{y})\right) * \sin \emptyset \\
& \mathrm{m}_{\mathrm{t}}^{\mathrm{p}}(\mathrm{y})=\mathrm{H}_{\mathrm{Z}}^{\mathrm{P}}(\mathrm{y}) *\left(\mathrm{X}_{\mathrm{o} . \mathrm{j}}(\mathrm{y})-\mathrm{X}_{\mathrm{c} . \mathrm{p}}(\mathrm{y})\right) * \cos \emptyset \\
& \mathrm{X}_{\mathrm{o} . \mathrm{j}}(\mathrm{y})=0.33 \mathrm{C}(\mathrm{y}) \\
& \mathrm{X}_{\mathrm{c} . \mathrm{p}}(\mathrm{y})=0.25 \mathrm{C}(\mathrm{y}) \\
& \mathrm{M}_{b}^{\mathrm{p}}(\mathrm{y})=\int_{0.5 \mathrm{~b}}^{\mathrm{y}}\left[\frac{\mathrm{Q}_{\mathrm{z}}^{\mathrm{P}}(\mathrm{y})}{\cos \emptyset}+\mathrm{m}_{b}^{\mathrm{p}}(\mathrm{y})\right] \mathrm{dy} \\
& \mathrm{M}_{\mathrm{t}}^{\mathrm{p}}(\mathrm{y})=\int_{0.5 \mathrm{~b}}^{\mathrm{y}}\left[\mathrm{m}_{t}^{\mathrm{p}}(\mathrm{y})\right] \mathrm{dy}
\end{aligned}
$$




\section{Fuselage Analysis}

Firstly the geometrical model of the fuselage was created in ABAQUS as shown in Fig. (4), then the material properties of skin, frames and longerons was defined as demonstrated on Table (3).
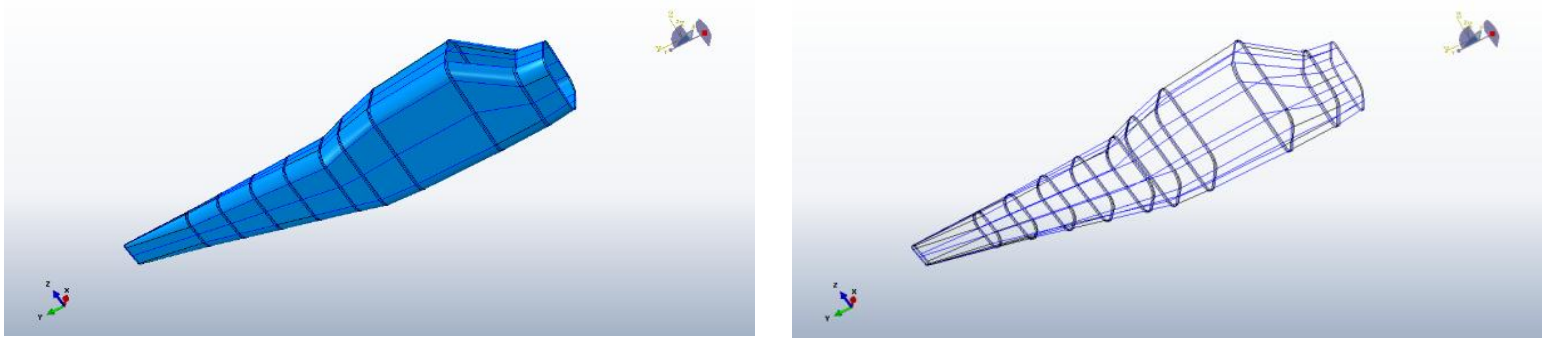

Fig. 4 ABAQUS model

Table 3 Mechanical properties of material

\begin{tabular}{c|c}
\hline \hline Alloy name & $\mathrm{Al} \mathrm{2024}$ \\
\hline Modulus of elasticity & $73.1\left[\mathrm{~N} / \mathrm{mm}^{2}\right]$ \\
Poisson's Ratio & 0.33 \\
Yield tensile stress & $324\left[\mathrm{~N} / \mathrm{mm}^{2}\right]$ \\
Shear strength & $283\left[\mathrm{~N} / \mathrm{mm}^{2}\right]$ \\
Density & $2.78\left[\mathrm{~g} / \mathrm{cc}^{3}\right]$ \\
\hline
\end{tabular}

Loading and boundary conditions were applied to the model as shown in Fig. (5).

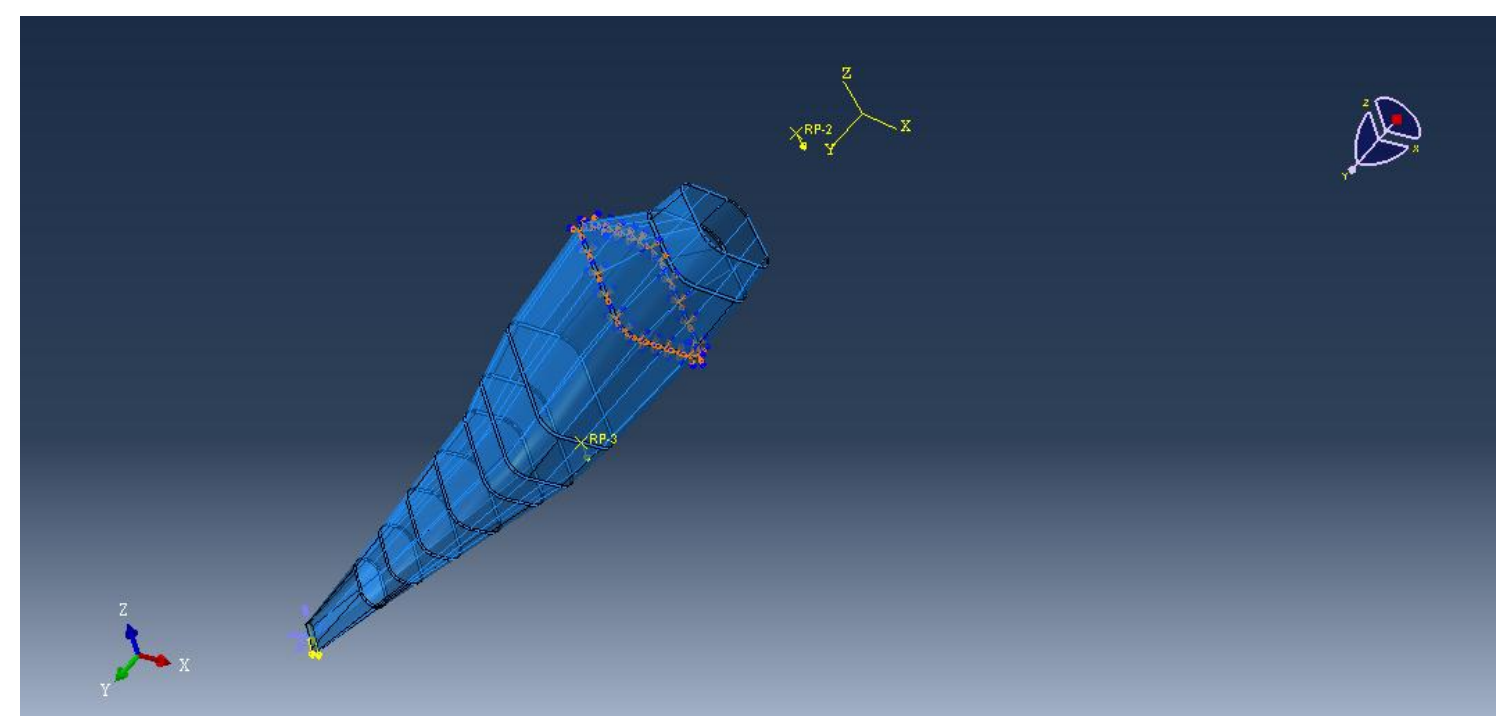

Fig. 5 Boundary conditions and applied loads 
Then different types of meshes has been created according to the structure component functions and shapes, the B31 beam element applied to longerons and frames where the S4R shell element is applied to the skin as shown in Figs. (6) and (7), respectively.

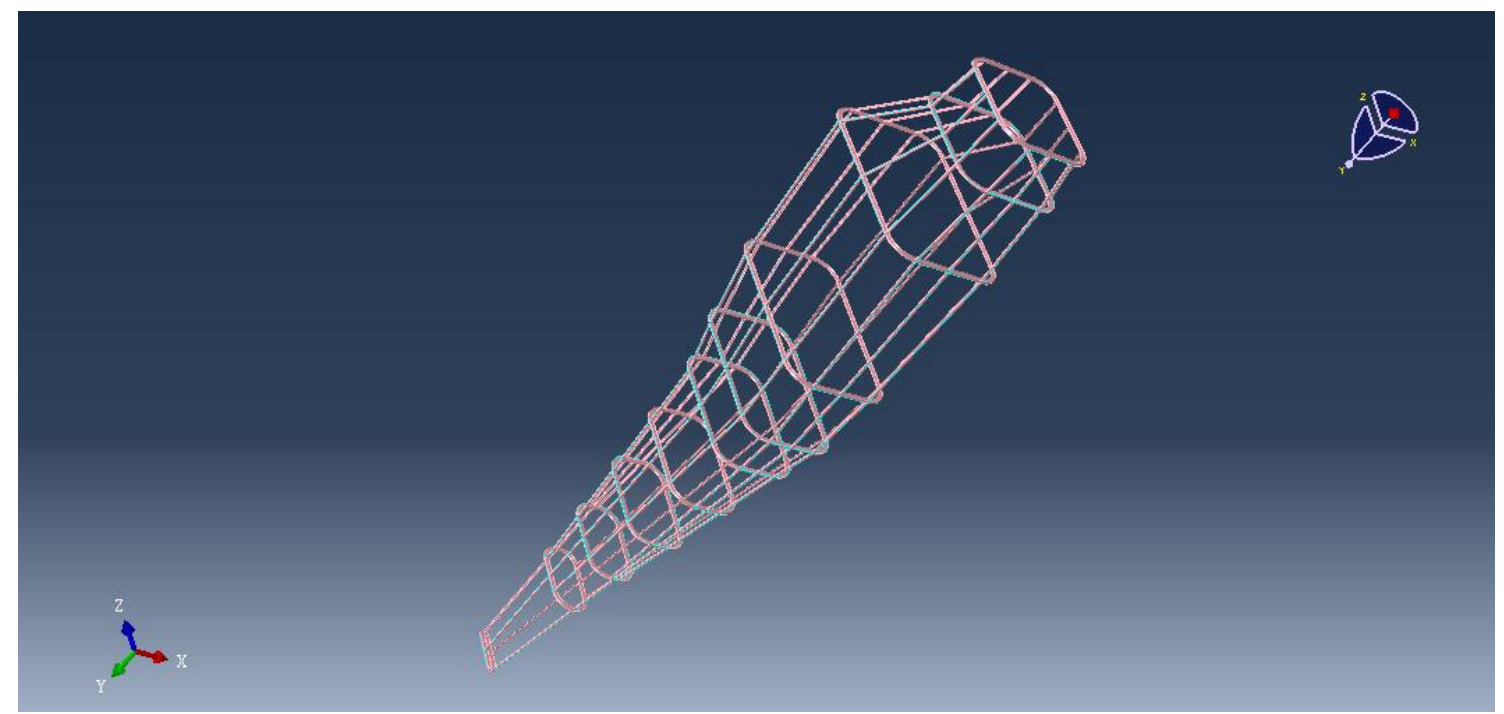

Fig. 6 Mesh of frames and longerons

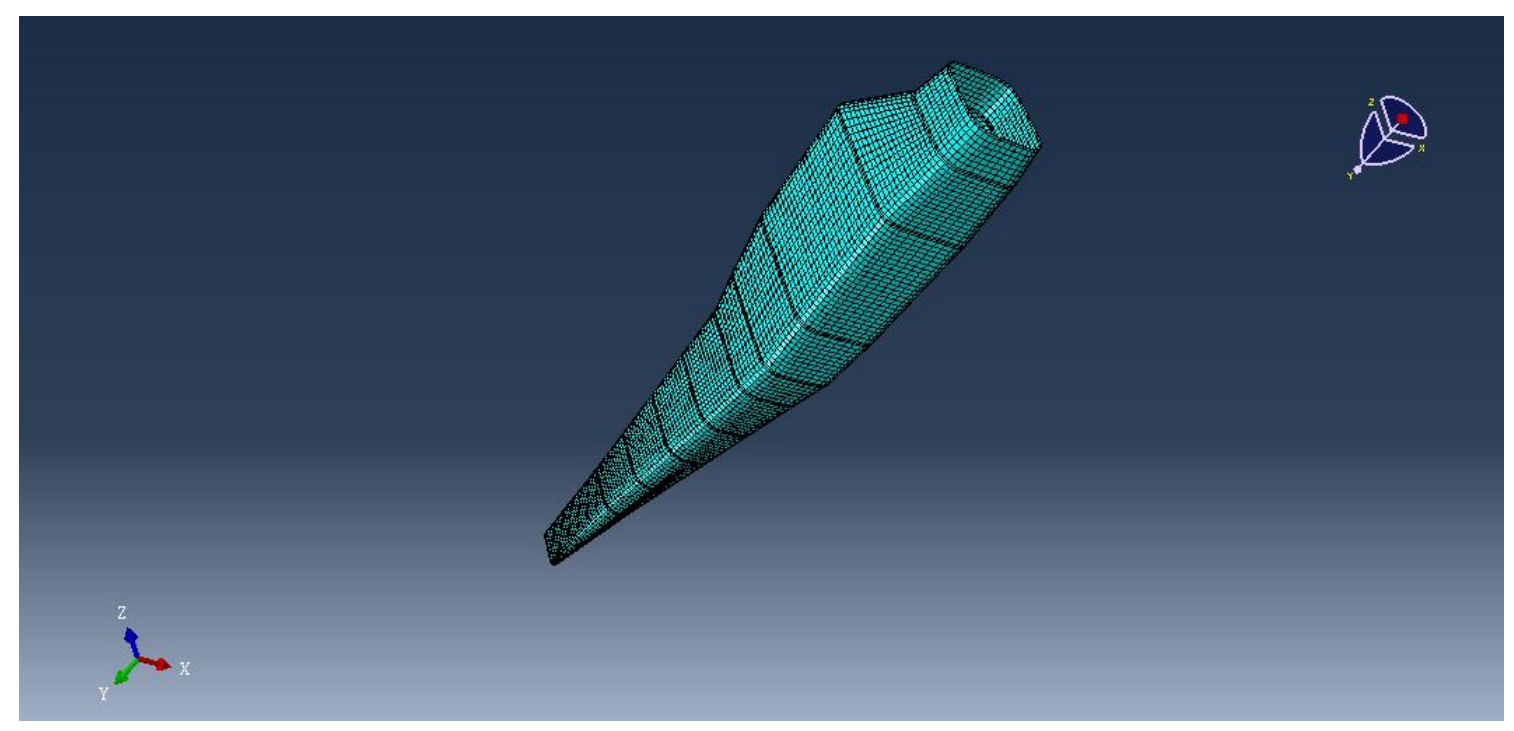

Fig. 7 Mesh of skin

Finally, the model had been analyzed in linear static analysis. 


\section{Results}

The obtained shear forces, bending moments are twist moments are illustrated in Figs. (8), (9) and (10), respectively.

H. Tail

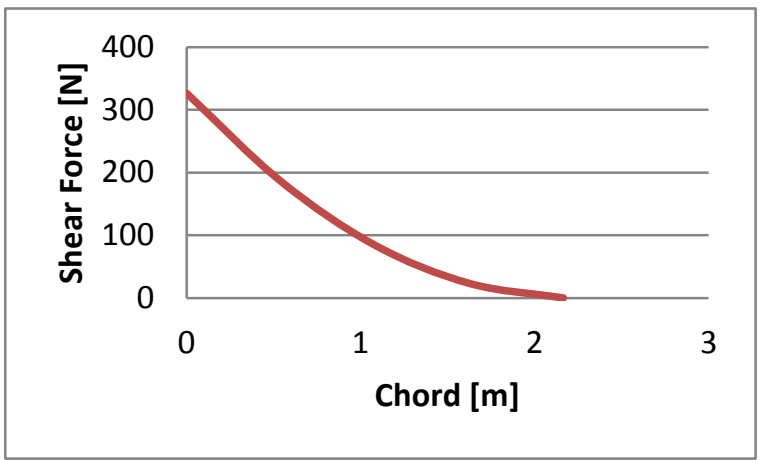

V. Tail

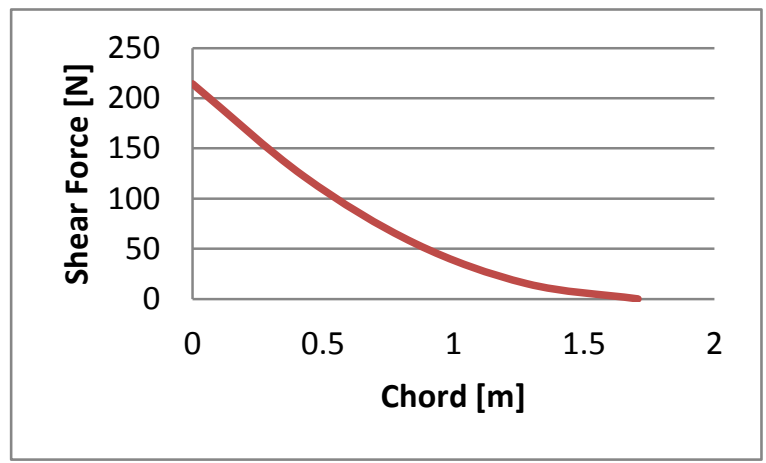

Fig. 8 Shear force diagrams

H. Tail

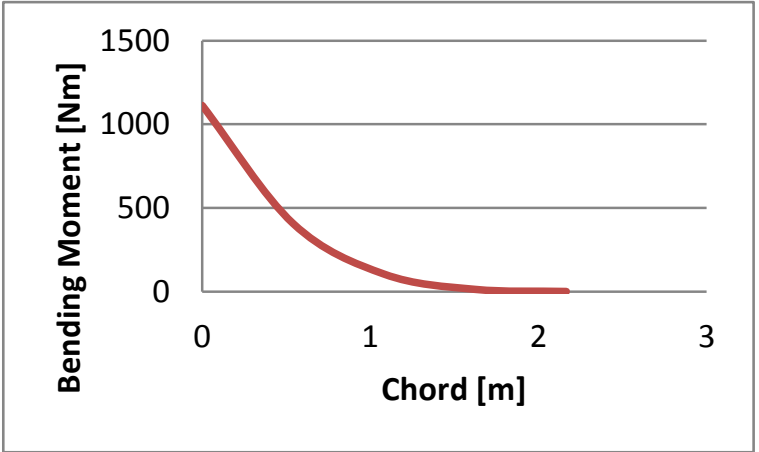

V. Tail

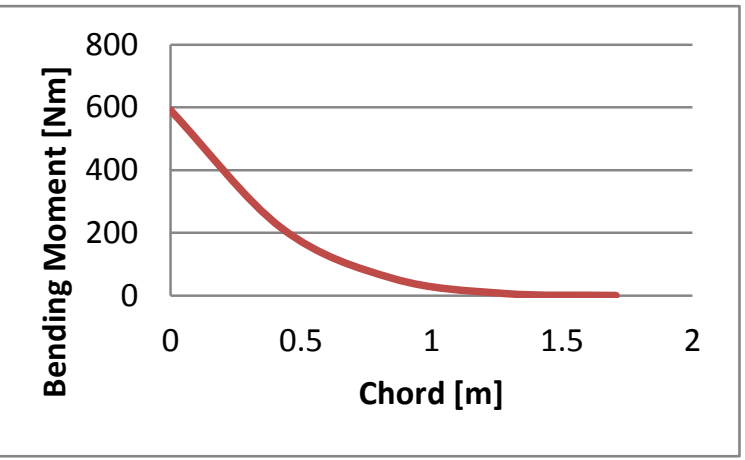

Fig. 9 Bending moment diagrams

H. Tail

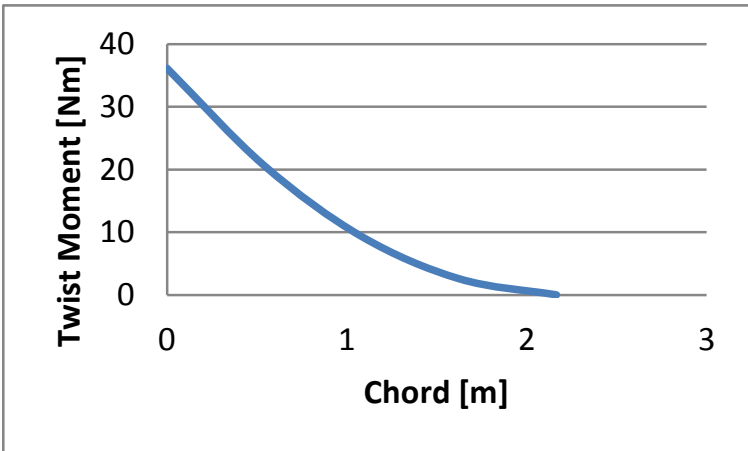

V. Tail

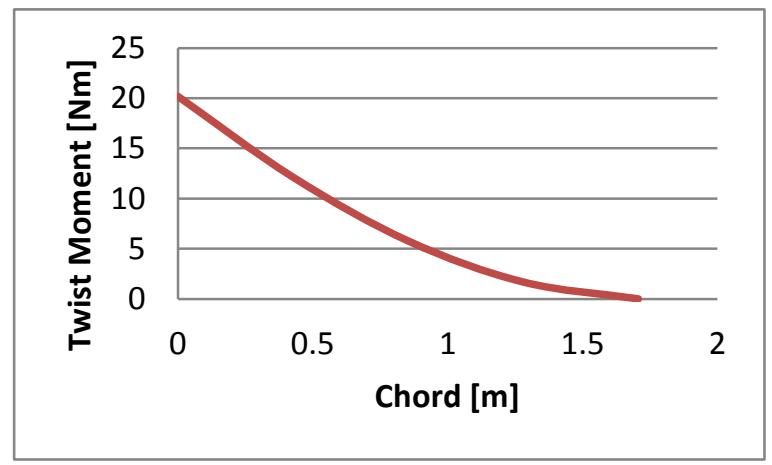

Fig. 10 Twist moment diagrams

The obtained von-Mises stress results of skin and frames and longerons are illustrated in Figs. (11) and (12), respectively, while Fig. (13) shows the von-Mises stress of the whole model. Also, Fig. (15) represents the total displacement of the skin. 


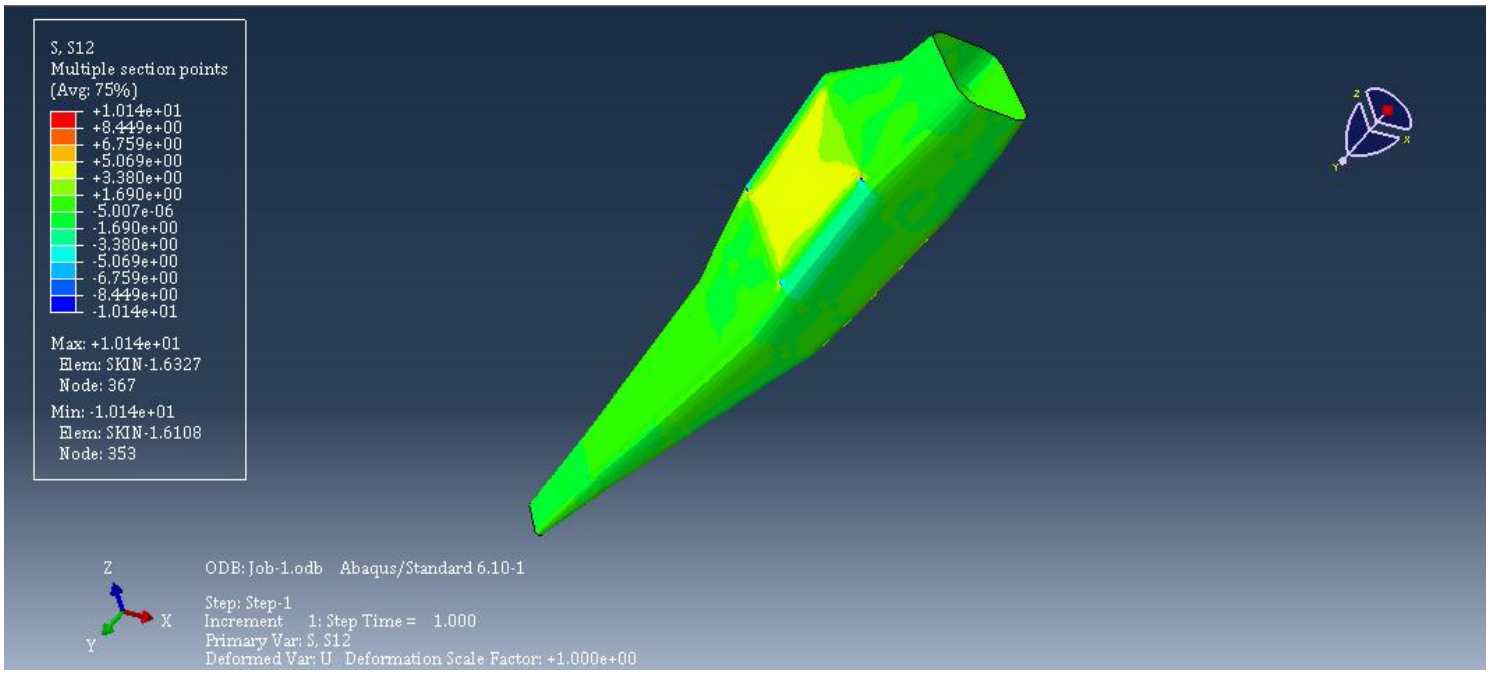

Fig. 11 von-Mises stress in skin [N/mm $\left.{ }^{2}\right]$

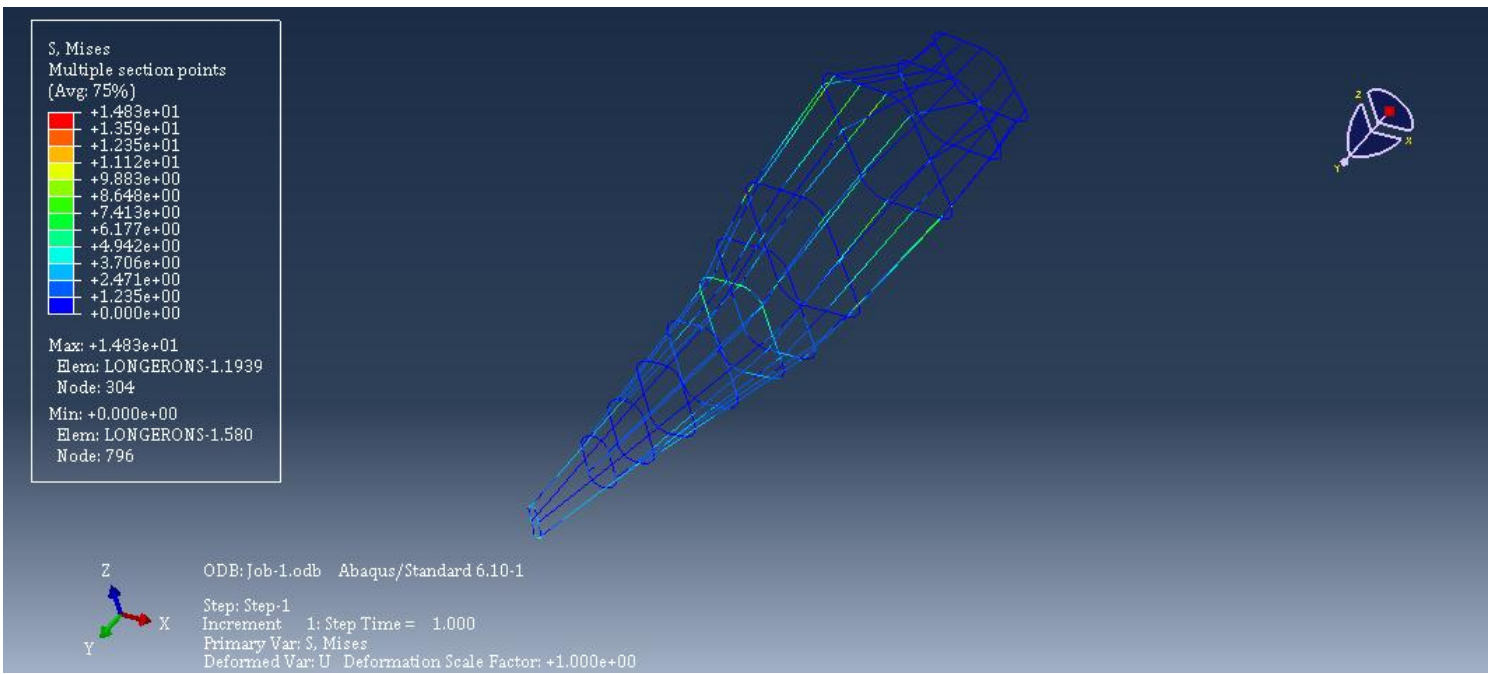

Fig. 12 von-Mises stress in frames and longerons $\left[\mathrm{N} / \mathrm{mm}^{2}\right]$

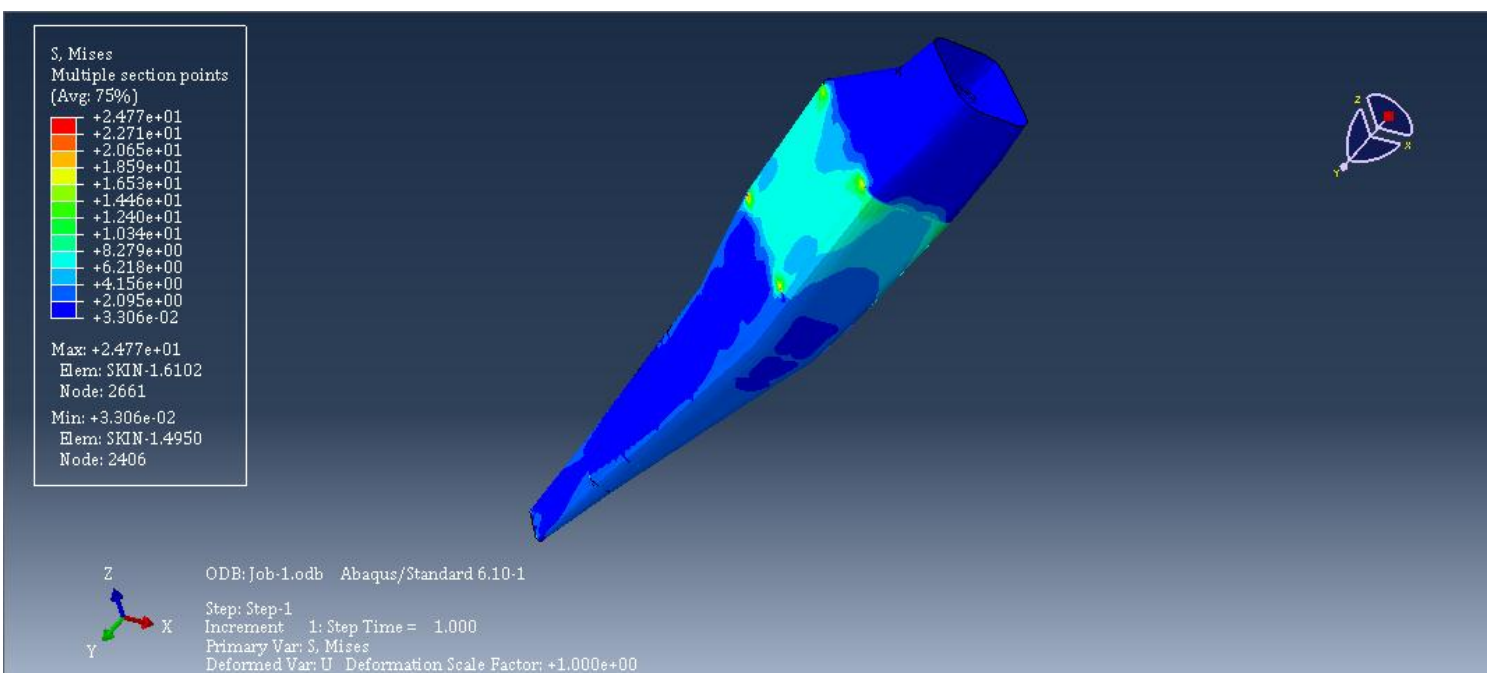

Fig. 13 von-Mises stress in model $\left[\mathrm{N} / \mathrm{mm}^{2}\right]$ 
The obtained shear stress of skin is illustrated in Fig. (14) as shown below.

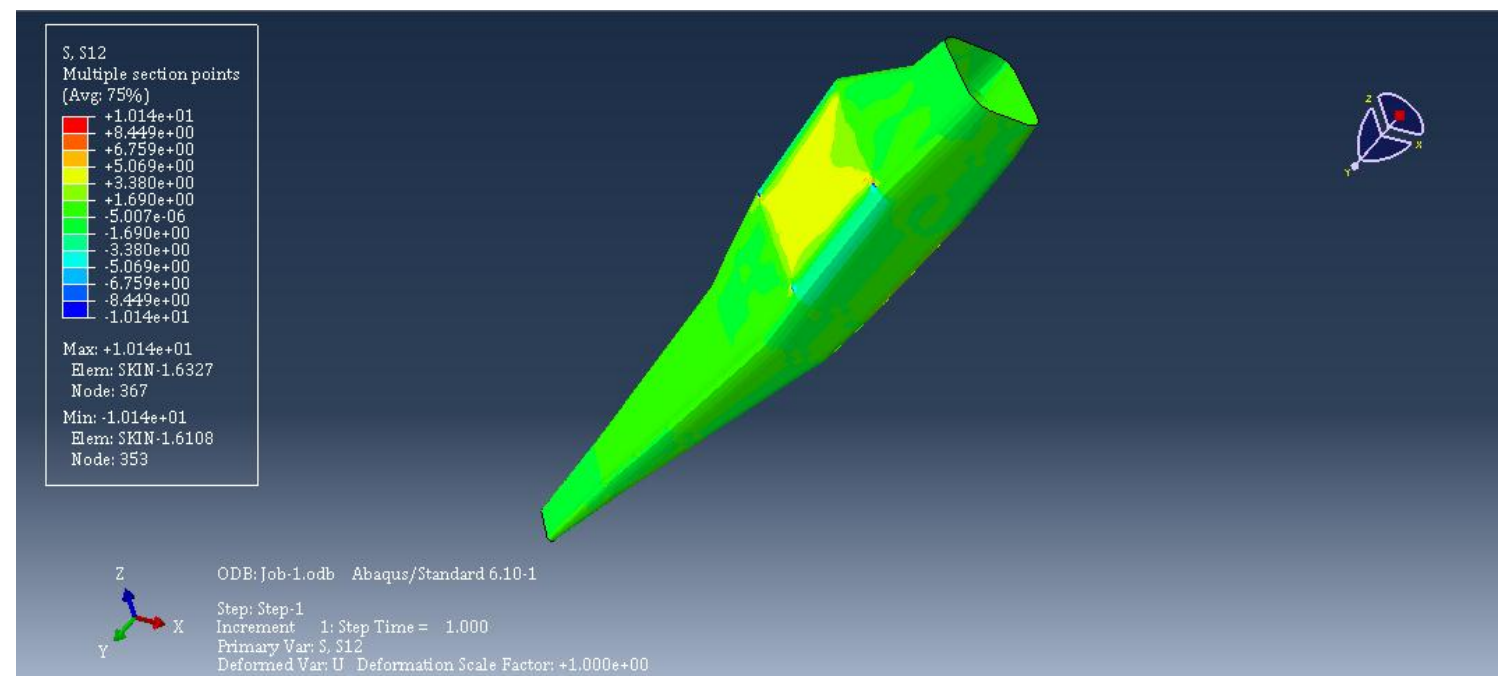

Fig. 14 Shear stress in skin $\left[\mathrm{N} / \mathrm{mm}^{2}\right]$

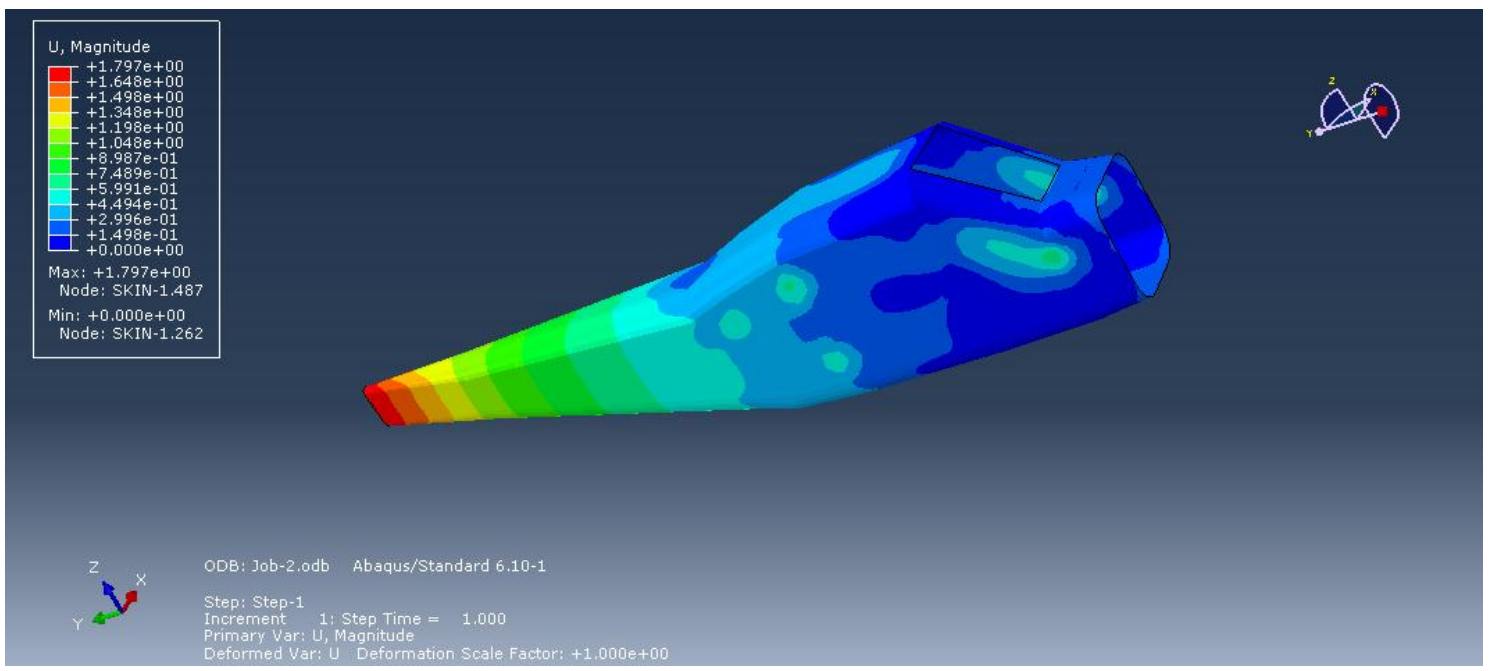

Fig. 15 Total displacement $[\mathrm{mm}]$

Static margins of safety are computed based on maximum applied stress which developed from FEA procedure and materials allowable stresses, the minimum safety margin of parts has been presented on Table (4).

Table 4 Safety margin

\begin{tabular}{l|c|c|c}
\hline \hline \multicolumn{1}{c|}{ Parameter } & $\begin{array}{c}\text { Actual } \\
{\left[\mathrm{N} / \mathrm{mm}^{2}\right]}\end{array}$ & $\begin{array}{c}\text { Allowable } \\
{\left[\mathrm{N} / \mathrm{mm}^{2}\right]}\end{array}$ & Safety Margin \\
\hline von-Mises stress [1] & 24.77 & 324 & 13.1 \\
Shear stress & 10.14 & 283 & 27.9 \\
\hline \hline
\end{tabular}




\section{Conclusions}

It can be concluded that:

$\circ$ For the current design, the bending and shear margins of safety are positives.

$\circ$ The obtained values are good enough which show ample strength for the fuselage structure.

○ The structure is safe within the design speed.

This work is just a preliminary design, more analysis is required to verify the above conclusions for the various flight conditions, namely by adding the loads which have been neglected in present work and should to be amended by buckling analysis.

\section{References}

[1] Ismail A. Yousif, Mohammed. Elhadi A. E, Preliminary Sizing of an Agricultural Aircraft, 14th International Conference on Aerospace Sciences \& Aviation Technology, Military Technical College, Kobry Elkobbah, Cairo, Egypt; May 24 - 26, 2011.

[2] JAR-VLA. Joint Aviation Regulation,-Very Light Aircraft, European standard, April 2009.

[3] A. M. Gubaratalla Ali, M. Elhadi A. E, Preliminary Design of the Tail Unit of a Newly Designed Agricultural Aircraft; 14th International Conference on Aerospace Sciences \& Aviation Technology, Military Technical College, Kobry Elkobbah, Cairo, Egypt; May 24 - 26, 2011.

[4] Roskam J., airplane design: part III, layout design of cockpit, fuselage wing and empennage: cutaways and inboard profiles, Roskam j., airplane design: part IV, layout design of landing gear and system. 